\title{
BLINDNESS CAUSED BY FRACTURE OF THE OPTIC CANAL: NEW ADVANCES IN TREATMENT
}

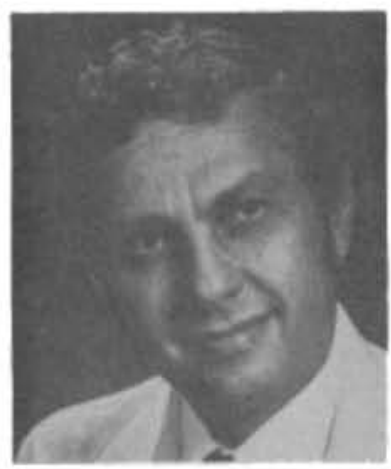

Mutaz B. Habal, M.D., F.R.C.S. (C), F.A.C.S.

Director, Tampa Bay Center for Cranio-Facial Surgery.

801 W. Buffalo Avenue, Tampa, Florida 33603

DOI: http://dx.doi.org/10.5915/13-4-11972

\section{SUMMARY}

The optic nerve can be injured indirectly by blunt trauma to the frontoorbital region. The mechanism of injury is related to trauma of the nerve in the tight, bony optic canal. Neurovisual transmission in the canal is interrupted by pressure on the nerve. The conventional management includes careful observation and supportive treatment. Recent interest in this unique clinical problem has prompted the development of new techniques to decompress the injured optic canal extracranially; these approaches have produced encouraging results. Another dividend of the method has been the mapping of the optic nerve region under magnification, using the operating room microscope. Any gain of vision, partial or complete, is well appreciated by the patient and the physician.

Isolated injury to the optic nerve is usually encountered where the nerve, with its central retinal artery and the ophthalmic artery, passes through the tight, bony optic canal. Any injury to the bony canal, such as hemorrhage, sudden swelling. contusion or fracture in its vicinity will cause compresison of the optic nerve, resulting in loss of vision or visual impairment. The optic nerve, which is the second cranial nerve, is unlike the rest of the cranial nerves. Since it is completely surrounded by dura in the optic canal, injury does not result in regeneration. even if the damage is incomplete. Little evidence points to the presence of neuropraxia in the optic nerve. It is important to point out these facts to a patient being treated for visual impairment related to isolated or traumatic optic nerve injury. The optic nerve injury under discussion is distal to the optic chiasm and extends to the level of the entry of the nerve to the oculus. The major part of the optic nerve injured by trauma is within the bony canal14, 15, 16: isolated injury to the optic nerve usually takes place in that region.
Since the intracranical part of the nerve is loose proximally as well as distally (interorbital portion). these last two segments are less likely to be injured.

\section{ETIOLOGY}

The causes of optic nerve injury can vary from a simple optic canal fracture to a massive cranioorbital injury resulting in brain damage and multiple craniofacial fractures. The most common cause, however, is a massive trauma of the frontoorbital region. When decompresison of the nerve is to be considered ${ }^{23},{ }^{24}$ in the differential diagnosis, it is important to make sure that the injury is related to the optic nerve and its tract rather than to the more obscure optic tracts in the midcranial fossa. There are usually many associated problems; however, in rare instances, the injury may be an isolated optic canal fracture ${ }^{18}, 2^{23}, 2^{27}, 28$. The following discussion is primarily related to this last problem.

\section{TYPES OF OPTIC NERVE INJURY}

The optic nerve can be injured and its function impaired by contusion, edema, hematoma, transection or compression $15,16,17,21,22$.

Concussion can be incurred after a massive trauma. This may or may not be followed by edema of the nerve. A contusion at the fracture line after trauma will lead to interference with visual neural transmission. The tracts will probably have impaired function. Traumatic edema in the optic canal produces pressure in the tight space of the optic canal. This problem may be relieved during the natural course of the edema. An injury or discontinuity in the major blood vessels passing through the optic canal will usually result in pressure on the optic nerve and impaired transmission due to hematoma around the optic nerve. Evacuation of the clot to release the pressure may be a major factor in the return of vision. 
Complete division of the optic nerve is the most devastating cause of loss of vision. No evidence to date reports repairs under any circumstances that have resulted in any return of function to the nerve. Direct compression of the optic nerve produced by a linear fracture in the canal is another cause of loss of vision. Release of the pressure in the major factor in the return of neurovisual function.

\section{Natural History}

The natural history of an isolated acute optic nerve injury caused by trauma is generally complete and permanent loss of vision on that side. It is a grave problem when vision is lost traumatically and cannot be regained despite all known advances in medicine. Few patients reported in the literature experience spontaneous partial return of vision after severe injury to the optic nerve. The acute optic nerve injury is unusual, and the natural history of the problem may or may not apply to all patients with sudden loss of vision after acute isolated trauma to the optic nerve.

Sporadic patient histories reported in the literature indicate that a small percentage $(10-25 \%)$ may regain partial vision after a period of time. This spontaneous visual acuity return is slow and partial, in contrast to that gained by surgical decompression, which is immediate and may be complete ${ }^{711}{ }^{17}$.

\section{Diagnostic Procedures}

Medical history and complete physical examination are important in determining loss of consciousness and associated brain injury. Examination of the orbit and its contents is very important. Any apparent fractures should be noted. Visualization by funduscopic examination of the retina and the optic "cup" is also important, as is visualizaton of the optic disc. Pulsations and engorgement in the retinal veins should be noted. The presence of papilledema is usually a very telling sign. It is very important to know the presence or absence of visual field defects in the patient follow-up. Knowledge of any changes in the visual fields on the nonaffected side is an important factor in determining the presence of injury at the leve] of the optic chiasm toward the cortical area and is important to patient follow-up for evaluation of disease.

Visually evoked response (VER) is detected by transducers on the occipital cortex from direct stimulation of the optic nerve by a light source. The unaffected eye may be covered first to determine the degree of conduction in the affected eye. Then the unaffected eye is studied separately, since each eye contributes to bilateral cortical stimulation.

Pupillary responses are evaluated by studying the responses on the affected side; whether or not an Argyll Robertson pupil is present, sensory stimulation and responses are evaluated. Evaluation of the supraorbital fissure contents is also important to ascertain.

$\mathrm{X}$-ray diagnostic studies such as plane X-rays of the facial region, posteroanterior Waters views, and Caldwell views are essential. Polytomograms of the optic canal and facial bones are used when clinical evaluation points to their necessity.

Complete study by computerized axial tomography (CAT) is of the utmost importance, especially with recent knowledge of horizontal and sagittal planes of the various levels in the central nervous system. Knowledge in this field is quite new, and the scan may or may not be conclusive, although the optic nerve is easily visualized on the scan from the level of its entrance in the retina to the splenum sphenoidale.

The symptoms associated with an isolated fracture are usually epistaxis and pain in the frontoethmoidal region on the affected side. Headaches, nausea, and vomiting may be present.

\section{Methods of Treatment and Management}

Many treatment modalities have been advocated in the past, but the current consensus as to the accepted method of treatment is the classic approach, which is generally conservative (nonoperative).

\section{The Conservative Approach}

The accepted mode of treatment for an acute injury is conservative unless there are associated dural cerebrospinal fluid leaks which, in most patients, will close spontaneously. It is also believed that by the time the patient reaches the treating physician, irreversible changes have already occurred in the end receptors of the retina. The optic nerve, which acts as a tract, is similar to the spinal cord. Injury to the tract results in permanent damage, rather than regeneration over a period of time, unlike the situation with the other cranial nerves, which may regenerate.

Therefore, in most medical centers, the currently accepted mode of treatment is to advise the patient that the damage is permanent. The patient may also be advised that associated changes may take place in the retina as early as the first 24 hours. As previously pointed out, sporadic reports in the literature indicate that ten to thirty percent spontaneous regaining of partial vision may be $\operatorname{seen}^{2},{ }^{21},{ }^{25}$. However, when spontaneous return of vision is seen, it is usually slow and incomplete. Visual acuity is not regained.

\section{Steroids}

Steroids are sometimes advocated in massive doses, especially when treating progressive loss of vision due tc a slow swelling of the optic nerve in the optic canal resulting from injury or related to hematoma or hemorrhage in that vicinity. It is believed that massive 
doses of steroids may reverse the process and result in at least partial restoration of some of the visual fields and visual acuity on the affected side. However, in the presence of open communication with contamination or dural tears with accompanying cerebrospinal fluid leaks, the use of steroids may jeopardize the patient's life by increasing the chances of contracting sudden meningitis or cerebritis.

\section{Decompression}

Decompression of the optic nerve is not new. Reference to its application in the literature has waxed and waned since the turn of the century, but recently there has been more and more interest and enthusiasm in the application of that method of treatment, mainly because of advances in the application of microsurgical techniques ${ }^{11}, 12,17$.

Results are inconsistent, and they do not suggest a straightforward prospective study of any given problem. However, any gain or achievement in a blind eye is always welcomed by both the patient and the treating physician, providing the treatment does not add major mortality or further morbidity to the original problem. Decompression can be intracranial or extracranial.

Intracranial decompression requires a craniotomy, which may be contraindicated, particularly when there are other disorders with or without brain concussion or contusion. It is not advisable to retract on a contused brain for the period of time which would be necessary for adequate exposure of the optic canal for complete optic nerve decompression intracranially. Therefore, it is felt that intracranial decompression is a high price to pay for the questionable improvement that the patient may obtain. This technique is presently reserved for very rare problems. Some reports in the literature encourage the technique using the direct, intracranial, intradural route $3,18,19,20,21,28$.

Extracranial decompression can be achieved by the transorbital", transethmoidal ${ }^{8}$, and transantral16 approaches. However, Fukado popularized and disseminated the knowledge of the extracranial approach via the transethmoidal approach, and presented his spectacular results ${ }^{6}, 8_{10}$. A small external incision is made in the frontoethmoidal region and the ethmoidal cells are opened, providing direct and accurate access to the optic canal with the aid of the operating microscope. Knowledge of surgical anatomy of this region is of the utmost importance. The area can be decompressed easily and quickly. Most studies using this mode of treatment are recent, and overall results are not well accepted in the daily course of treatment in every medical center.

Success with this approach is limited to those well experienced in this technique. The transorbital approach utilizes a similar incision, exposing the optic nerve, and the globe with its periorbitum is retracted laterally. This decompression can be done without traversing the dura or the sinus mucosa ${ }^{11}, 12$. The transantral approach is via a Caldwell Luc incision: the ethmoidal air cells are exposed and traversed; the dissection is then similar to the one described for the transethmoidal approach. The optic nerve and its canal are then visualized in a similar manner ${ }^{\text {it }}$. The fine anatomical landmarks are usually noted with al these techniques. If the optic nerve is decompressed transorbitally, the optic ring, which is the thickest part of the distal optic canal, is opened first. With the transethmoidal approach, the optic tubercle is the landmark that is followed; it appears as the bulge of the optic canal into the ethmoidal air cells. Once the canal is opened at any point, the decompression can be completed throughout the fixed part of the nerve in the canal, thus freeing that portion of nerve from its liability to immobilization in the canal.

The problems and the hazards of decompression are directly related to the contraindications, which, at the present time, are difficult to delineate. It is acceptable to say that major contraindications are encountered when any patient with acute injury cannot be anesthetized. The hazard may be complicated by an extended fracture from the optic canal to the cranioorbital zone, which may injure the remaining intact optic nerve, since that is the remaining source of vision for the patient. Tears in the dural space that may precipitate an unwarranted cerebrospinal fistula should be avoided. All such problems, their avoidance, and treatment should be weighed against the accomplishment of return of vision. Infection from any source of extradural contamination can be avoided with the appropriate preventive antibiotics.

\section{REFERENCES}

1. Ambos E. Fattinger W: Ophthalmological complications with special regard to decompression of optic nerve. Klin Med (Mosk) 22:460, 1967.

2. Arrata MW: Case of physiologic section of optic nerve with late quasi-total recovery. Arch Ophthalmol 34:587, 1974.

3. Beuthner D: Consideration of optic nerve decompression in relation to a 10-year review of management in fractures of anterior base skull. Laryngol Rhinol Otol (Stuttg) 53:830, 1974

4. Chuden H: Decompression of retrobulbar space and optic nerve. HNO 22:320, 1974.

5. Freyss G., Nancy P., Soudant J: Optic nerve decompression through transethmoidalsphenoidal approach. Synopsis of the European Society of Maxillofacial Surgery, Paris, 1975, p. 16

6. Fukado Y: Diagnosis and surgical correction of optic canal fracture after head injury. Ophthalmologica (Suppl) 307, 1969. 
7. Fukado Y: Results in 400 cases of surgical decompression of the optic nerve. Proceedings of the Second International Symposium of Orbital Disorders, 1973, vol. 14, p. 474.

8. Fukado Y, Nagai M: A five-year review of ocular injuries. Acta Soc. Ophthalmol. Jpn 22:70, 1971.

9. Fukado Y, Nagai M: A five-year review of ocular injuries. Acta Soc. Ophthalmol Jpn 75:972, 1971.10. Fukado Y: Results of 350 cases of surgical decompression of optic nerve. Trans Ophthalmol Soc. NZ 25:96, 1973.

11. Habal MB, Maniscalco JE, Rhoton AL: Microsurgical anatomy of the optic canal: observations on the anatomical relations and exposure of the optic nerve, Surg. Forum 25:542, 1976.

12. Habal MB, Maniscalco JE, Rhoton AL: Microsurgical anatomy of the optic canal: correlates to optic nerve exposure J. Surg. Res. 22:527, 1977.

13. Harada Y: Decompression of optic nerve using trans-maxillary approach. Otolaryngology (Tokyo) 42:117, 1970.

14. Hirakawa K, Hori T: Mechanical study on traumatic optic nerve injuries. Neuro Med Chir (Tokyo) 11:34, 1971.

15. Imachi Y: Clinical and patho-histologic investigations on optic nerve lesions caused by head injuries. Acta Soc Ophthalmol Jpn 71:1874, 1967.

16. Kennerdel JS, Ambaugh GA, Myers EN: Transantral ethmoidal decompression of optic nerve fractures. Arch Ophthalmol 94: 1040, 1976.

17. Klose R: The direction of scar tissue following incision of optic nerve. Verh Anat Ges 66:373, 1971 .

18. Meyers E: Transorbital, Transethmoidal decompression of the optic nerve. Presented at the
OOOA Annual Meeting, Miami, 1976.

19. Mizukawa T: Operative treatment of traumatic lesions of optic nerve. Klin Monatsbl Augenheilkd 163:327, 1973.

20. Muller HR: Surgical treatment of traumatic injuries to optic nerve. Ber Dtsch Ophthalmol Ges 72:116, 1974.

21. Plane C, Sole P, Jonny P, et al: Section of optic nerve due to orbital injuries - electrophysiologic examination. Rev. otoneuroophthal 41:73, 1969.

22. Romer F, Muller U, Battey W: Surgical management of indirect traumatic lesions of optic nerve. Klin Monatsbl Augenheilkd 163:327, 1973.

23. Schmaltz B, Schurmann K: Traumatic damages of optic nerve: problems of etiology and optic therapy. Klin Monatsbl Augenheilkd.

24. Sedan MJ: Against initial and systematic surgical action in a number of cases of indirect trauma of optic nerve. Rev Otoneuroophthalmol 40:6, 1968.

25. Shalit S, Dujovny M, Manor R, et al: Neurosurgical aspects of traumatic lesions of optic nerve and chiasma. Harefuah 85:576, 1973.

26. Steimle R, et al: Traumatic injuries of optic nerve and microsurgery. Rev Otoneuroophthalmol 45:421, 1973.

27. Takahishi T: Pathological study of optic nerve disorders caused by head injuries. Acta Soc Ophthalmol Jpn 72:2353, 1968.

28. Walsh FB, Hoyte WF: Clinical Neuroophthalmology, Baltimore, Williams \& Wilkins. 1969, pp. 2362-2367.

29. Wennerstrand J, Galera R, Corsal GD: A method of decompression and mobilization of optic chiasma. Acta Soc Med Ups 72:272, 1967. 